\title{
Unresectable Esophageal Carcinoma
}

National Cancer Institute

\section{Source}

National Cancer Institute. Unresectable Esophageal Carcinoma. NCI Thesaurus. Code C128563.

A carcinoma that arises from the esophagus and is not amenable to surgical resection. 